Check for updates

The BMJ

Cite this as: BMJ 2020;369:m2416 http://dx.doi.org/10.1136/bmj.m2416 Published: 16 June 2020

\title{
Covid-19: Medical leaders call for urgent action to make hospitals safe
}

\section{Gareth lacobucci}

NHS emergency departments cannot return to having patients waiting in corridors as the service recovers from the covid-19 pandemic, the head of the Royal College of Emergency Medicine has told MPs.

In an oral evidence session with the House of Commons Health and Social Care Committee on Tuesday 16 June, Katherine Henderson said that a return to overcrowded departments risked causing "enormous" harm to patients because of the danger of covid-19 spreading. She told the committee, "We didn't start this pandemic in a good place for emergency departments. They were at the most stressed they'd ever been. The old way involved emergency departments having elastic walls. We were never able to say we were at full capacity. We now need to recognise that we can't do that."

Henderson and Derek Alderson, president of the Royal College of Surgeons of England, who also gave evidence to the committee, each emphasised that the NHS needed to find safe ways to balance the treatment of patients with covid-19 with emergency and planned care.

Henderson said that although it was good that some people were coming back to emergency departments after staying away during the height of the pandemic, the NHS needed to convey the "difficult message" that some patients could be seen more appropriately in primary care or could call NHS 111.

"We need to have confidence that people with an emergency can come to an emergency department and be safe," she said.

A joint written memorandum submitted by both colleges to the evidence session contained findings from a poll of 1167 members of the Royal College of Emergency Medicine that found that seven in 10 did not think they had enough side rooms for patients in their emergency department.

The memorandum also identified the need to treat a "hidden waiting list" of patients who have not yet been referred and to avoid further suspension of treatments if there is a second wave of covid-19.

Alderson said that the suspension of almost all planned NHS surgery during the pandemic had created a huge backlog of patients waiting for treatment, with some, such as those waiting for joint replacements, waiting "unacceptably long times" for their surgery.

The memorandum also included findings from a survey of 1692 surgeons, a third of whom reported that they did not yet have access to "covid-light" hospital sites, where planned surgery could take place with lower risk, even in the event of a second wave of covid-19.
Alderson called for urgent action to develop more covid-light sites and said the government should extend its deal with the private sector it had struck to increase capacity during the pandemic. He said, "At the moment we believe that the capacity within the NHS resource alone is insufficient to get surgery started again and maintain a sustainable resilient service. We believe it is essential that we retain access to independent sector facilities for NHS patients."

But he added that restarting elective services was more complex than stopping them and warned it would be unrealistic to expect long waiting lists that existed even before the covid pandemic to be cleared in weeks. He said, "We have to restore confidence in the public that they can have an elective operation safely. Dealing with the backlog is not something that's achievable simply in weeks-this is certainly many months, and it may take us a few years to catch up.” 